Journal of Mathematics and Statistics 6 (4): 468-480, 2010

ISSN 1549-3644

(C) 2010 Science Publications

\title{
Vedas and the Development of Arithmetic and Algebra
}

\author{
Gurudeo Anand Tularam \\ Mathematics and Statistics, Faculty of Science, Environment, \\ Engineering and Technology (ENV), Griffith University
}

\begin{abstract}
Problem statement: Algebra developed in three stages: rhetorical or prose algebra, syncopated or abbreviated algebra and symbolic algebra-known as "school algebra". School algebra developed rather early in India and the literature now suggests that the first civilization to develop symbolic algebra was the Vedic Indians. Approach: Philosophical ideas of the time influenced the development of the decimal system and arithmetic and that in turn led to algebra. Indeed, symbolic algebraic ideas are deep rooted in Vedic philosophy. The Vedic arithmetic and mathematics were of a high level at an early period and the Hindus used algebraic ideas to generate formulas simplifying calculations. Results: In the main, they developed formulas to understand the physical world satisfying the needs of religion (apara and para vidya). While geometrical focus, logic and proof type are features of Greek mathematics, "boldness of conception, abstraction, symbolism" are essentially in Indian mathematics. From such a history study, a number of implications can be drawn regarding the learning of algebra. Real life, imaginative and creative problems that encourage risk should be the focus in student learning; allowing students freely move between numbers, magnitudes and symbols rather than taking separate static or unchanging view. A move from concrete to pictorial to symbolic modes was present in ancient learning. Real life practical needs motivated the progress to symbolic algebra. The use of rich context based problems that stimulate and motivate students to raise levels higher to transfer knowledge should be the focus of learning. Conclusion/Recommendations: The progress from arithmetic to algebra in India was achieved through different modes of learning, risk taking, problem solving and higher order thinking all in line with current emphasis in mathematics education but at rather early stage in human history.
\end{abstract}

Key words: Vedic philosophy, mathematics education, ancient Indian mathematics, development of algebra, mathematical knowledge, symbolic algebra, Vedic literature

\section{INTRODUCTION}

In the past many western scholars thought that Indians had not done any original work till the time of Bhaskara II but as this paper shows, this is indeed far from the truth. In fact, the the growth of Indian mathematics did not stop with Bhaskara II either as will be noted that some aspects of Indian mathematicians may have been rediscovered by Europeans later - the development of number theory, the theory of indeterminates infinite series expressions for sine, cosine and tangent, computational mathematics (O'Connor and Robertson, 2000).

There has been a lack of research in the area of non-European mathematics in the past but the academic interest in this area has increased (Bailey and Borwein, 2010; Dutta, 2002; Joseph, 1991, O'Connor and Robertson, 2000: Hayashi, 1997). Research now suggests that some early non-European mathematical works form the basis of some mathematical knowledge; for example, the use of symbols such as letters of an alphabet to represent unknowns as evident in Hindu algebra, developed from Hindu arithmetic; that was in turn advanced by the use Hindu-Arabic symbols of the decimal system (Cajori, 2007, Tularam, 1993). The numerical system is Hindu rather than Arabic for the Arabs can be credited to passing it on to the West. AlBiruni cited in O'Connor and Robertson (2000) states "What we [the Arabs] use for numerals is a selection of the best and most regular figures in India". Further, Kerala mathematics (ADl200-1500) also showed advancement that led to the overall algebraic achievements of India; knowledge grew gradually to rather great heights of its time. The early arithmetical works in Harrappa, during the Vedic period, and the higher mathematics of the Jain, Aryabhata, Bhaskara and Kerala are all of great historical importance in the growth of mathematical knowledge. Kerala works on interpolation and infinite series expansions predates the similar European work by years (Joseph, 1991, Dutta, 2002). 


\section{J. Math. \& Stat., 6 (4): 468-480, 2010}

The concept of differentiation appears in India in AD950. The calculation of the instantaneous motion of the moon at a particular point in time is known as tatkalika-gati in Indian Astronomy and the concept of instantaneous motion is found in works of Aryabhata (AD499) and Brahmagupta (AD628). This review will show that based on very sound foundations India ultimately reached a high level of algebraic knowledge that eventually led to Manjula's (AD930) work. It seems that Manjula was the first to use an equation that included differentiation (O'Connor and Robertson, 2000; Joseph, 1991). Manjula was the first Hindu astronomer to state that the difference of the sines: sin $\mathrm{w}^{\prime}-\sin \mathrm{w}=\left(\mathrm{w}^{\prime}-\mathrm{w}\right) \cos \mathrm{w}$, where $\left(\mathrm{w}^{\prime}-\mathrm{w}\right)$ is small. That is, "true motion in minutes is equal to the cosine (of the mean anomaly) multiplied by the difference (of the mean anomalies) and divided by the cheda, added or subtracted contrarily (to the mean motion)". In the main, the first formula may be written as:

$u^{\prime}-u^{\prime}=v^{\prime}-v \pm e\left(w^{\prime}-w\right) \cos$

This in modern differential calculus may be written as:

$\delta \mathrm{u}=\delta \mathrm{v} \pm \mathrm{e} \cos \theta \delta \theta$

The method employed by Manjula to obtain this formula is not stated but the formula occurs also in the works of Aryabhata II (AD950), Bhaskara II (AD1150) and again in later writers. Moreover, Joseph (1991) found that Taylor series to second order was known to Indians years before Taylor.

One of the reasons that non-European mathematics failed to receive the attention it deserved earlier seems to be mainly due to the views held by colonial historians (O'Connor and Robertson, 2000; Vishnu, 2008). For example, Kaye (1915) argued that it was natural to seek for traces of Greek influence in later works of art and mathematics. There is evidence now to suggest Greek philosophy may be linked to or of a possible Indian origin (Cajori, 2007). The difficulty in translating of scripts in Sanskrit was another reason in that Sanskrit scripts had to be translated before mathematicians could appreciate their actual mathematical value. Joseph's (1991) study outlined the possibilities that may have led to the development of the vast knowledge of mathematics that we enjoy today; this includes the mathematical achievement of all major civilizations such as Mayan, Babylonian, Chinese among others.

In this study, the author explores Indian mathematics by briefly investigating early India and the
Vedic period-during which much of the foundations were laid for religious, philosophical and mathematical views of the world. The Vedic achievements are analysed to highlight the abstract and symbolic nature of their mathematics that ultimately led to the development of symbolic algebra (AD500). A more general view is then taken to compare achievements of the Indians with others such as the Greeks. Evidence is then provided that shows that Vedic Indians applied their algebra freely to other fields such as geometry and trigonometry. In the final section an overview is presented including implications for mathematics education based on the historical growth of algebraic knowledge perspective.

Early India: Some evidence exists that indicates that algebra in rhetorical form may have originated in Babylonia but this does not take into account the existence of knowledge in other contemporary (or even earlier) Indian civilizations such as Saraswati, Harappa, Mohendo Djaro. In Indian archeological sites many symbols were found but the written works are yet to be interpreted. There are reasons to believe that Harappa, Mohendo Djaro and others in India were equally advanced civilizations. The system of weights found are unique to the Western world. Commercial arithmetic existed because there was a considerable merchant class. The buildings suggest advanced planning of the cities, well structured designs of streets, sanitation and altars. There are sound reasons to believe that mathematics of some sophistication existed (Basham, 1975). It appears that decimals were used and knowledge of geometry is evident in surveying based on two units of length such as a foot of about 13.2 inches and a cubit of about 20.4 inches (Balsham, 1975). On the basis of evidence, Eves (1990) advocated that simple mathematics and engineering must have existed to aid the brick technology during this time.

After this early period, advancements were made in religion and philosophy in ancient India even though much research is needed to clarify various disputed points in literature. The Vedic period is conservatively dated around 2000-1500BC but scholars continue to believe that Vedic Aryans were foreigners to India even when archaeological evidence and the Vedic texts fail to support this assertion (Zeigler, 1972). None of the texts refer to an earlier homeland or items found in the civilizations resemble or reflect other European lands directly. Joseph (1991) is more cautious and unclear on this; he said "according to traditional though increasingly contentious view among historians a group of people descended from the north" (p.217). However, history also shows the reverse flow of knowledge in 


\section{J. Math. \& Stat., 6 (4): 468-480, 2010}

ancient times in that items found in Greece, Arabia and Iran suggest their Indian origin; particularly philosophical and mathematical knowledge. For example, idea such as vegetarianism and the concept of reincarnation is found in Pythagoras' work when such beliefs were not present in his lands (Gabre, 1897). Hindu numerals including zero and much of algebra show the reverse flow of knowledge outwards (Gabre, 1897; Joseph, 1991; Occonnor and Robertson, 2002; Singhal, 1969).

A challenge to the conservative views can be seen in the development that occurred in the Indus Valley. The Sanskrit language, Vedas, Upanishads, decimal system and other later mathematical feats originated from the Valley tradition and they have not been observed in the regions from where it is proposed that Aryans may have migrated from. The recent findings in Kalibangan in Punjab are of interest in that the findings include fire altars that were not found in earlier work and surprising absence of mother goddess figurines noted in most other areas (Kulke and Rothermund, 1990). This is a major aspect as it closely related to the back to the Vedas movement by Aryans in modern India (Dayananda, 1875). These findings suggest that such an Aryan Vedic tradition also existed during this period that is well expounded by Dayananda in his analysis of ancient texts. It is then not surprising that Kulke and Rothermund (1990) after seemingly establishing the origin of the Aryans conceded that "these holy scriptures do not give us a clue about the route of their migration and archaeological evidence is also missing. The origin of the Indo-Aryans is still shrouded in mystery" (p. 34). Presently, much of the Harappa script is still undeciphered but ancient Vedic texts of later origin exist and therefore need careful analysis.

Important religious and philosophical texts of the Hindus of India even today are the Vedas. In the main, the Rig, Atharva, Yajur and Sama Vedas are the four texts on which various philosophies and religious activities are based. Even to this day, the Vedas are the final authority to in India. The later Vedic texts (large in number) are also included in this literature and together referred to totally as the Veda in modern times. It is well accepted that the Vedic literature is one of the oldest surviving works of humanity dated around 1500BC. However others such as Tilak, relying on astronomical data, date them around 6000-4500BC (cited in Dunbar (1949) and Prakash (1989)). Jacobi cited in Kulke and Rothermund (1990) appears to confirm this claim. However, the exact time period is yet to be agreed upon but in brief, the Vedas contain mantras. A mantra is a Sanskrit word that translates closely to mean a succinct and abstract verse form believed to contain deeper knowledge (Joseph, 2000; Prakash, 1989; Cajori, 2007). Another verse form is named sutra or rule (formula), an almost incomprehensibly succinct, concise and abstract form such as "nikhilam sutra" (Vedic Mathematics, Maharaji, 1965). Such verses were written using the least amount of letters thus not easily deciphered by the uninitiated who would normally fail to realize their significance; not different to way the modern algebraic notation is unintelligible to the novice.

In earlier days the mantra/sutra knowledge was gained through initiation and an in depth meditation under the guidance of a guru (teacher). Not surprisingly, the literal meanings of mantras and sutras are often misleading (Joseph, 1991; Dayananda, 1875, 1958). Early writers referred to mantras as "...Vedic hymns are childish in the extreme; tedious, low, commonplace" (Muller, 1870). As a response, Swami Dayananda (1872) performed an in depth and rather intense study of all ancient Vedic texts for more than 15 years and succeeded to prove the statement above as false. The incorrect translations of Muller (and others) appeared to be basis for the lack of appreciation of the Vedic works; the ancient Sanskrit mantras' underlying Vedic messages were to not understood (Dayananda, 1875, 1958). However, Muller later conceded (see quotes later) before his death in his "The Six Systems of Indian Philosophy" when he wrote: "Whatever may be the date of the Vedic hymns, whether 1500 or 15000 $\mathrm{BC}$, they have their own unique place and stand by themselves in the literature of the world. They tell us something about the early growth of the human mind of which we find no trace anywhere else" (Muller, 1899)

The Sanskrit meaning of the Vedas is a storehouse of knowledge (Singhal, 1969; Basham, 1975). On page 129 of Swami Dayananda's $(1875,1958)$ text on "Introduction to the Commentary on Vedas", we find evidence in the Yajur Veda (1000BC) that not only provide proof of mantras stating the odd number sequence and arithmetical rules to derive infinite sequences but the mantras suggest the unaccountability of numbers and the decimal numbering (Yajur, 24-25). These and other verses not only refer to arithmetic, the science of numbers but also allude to algebra and geometry (Prakash, 1989; Dayananda, 1958). For example, in the first verse, 1 is added to 2 to make 3 and 3 added to 2 makes 5 and so on; it is recommended that this knowledge is to be learned by all who wish to progress in arithmetic. Another sequence follows in which 4 added to 4 makes 8 and 8 added to 4 gives 12 ; alluding to the process of multiplication by 4 through repeated addition. Both patterns appear to continue 
forever. Later, the Jain works develops this notion more fully leading to the concept of infinity (Joseph, 1991). It is implied that one should learn all combinations; one should decrease such sequences in a similar manner (Dayananda, 1958; Sharma, 2009; Carifio and Perla, 2010).

More recent evidence of fascination of large numbers is noted in O'Connor and Robertson (2000) quote.

To see clearly this early Indian fascination with large numbers, we can take a look at the Lalitavistara which is an account of the life of Gautama Buddha. It is hard to date this work since it underwent continuous development over a long period but dating it to around the first or second century $\mathrm{AD}$ is reasonable. In Lalitavistara Gautama, when he is a young man, is examined on mathematics. He is asked to name all the numerical ranks beyond a koti which is $10^{7}$. He lists the powers of 10 up to $10^{53}$. Taking this as a first level he then carries on to a second level and gets eventually to $10^{421}$.

Essentially, the mantras show an understanding of the decimal system during this period (at least 1000BC). Since decimals were found in the Indus Valley (4000-5000BC) region, its reappearance in in the so called Vedic times suggests a continuation of an ancient tradition involving decimal numbers. Prakash (1989) showed verses in Sanskrit that referred to large numbers written easily: a billion (Parardha) is mentioned in the Vedas. In Vedic texts, there is great interest in the nature of numbers, their factors, expressing of large numbers as powers of ten and in dividing time into smallest units and these appear aligned to the philosophy of the Vedas (Basham, 1975; Joseph, 2000; Prakash, 1989).

In relation to algebra, Dayananda (1958) was the first to propose that algebraic idea developed from the Vedas. He cited symbols from verses from the Sam Veda (1500BC) that he believed referred to the science of the unknown or variable. He suggested that the symbols used in the verses resemble symbols used in later Hindu algebra and the algebra in use today. He supported this claim by noting the use of symbols in mantras in the Sama Veda to indicate short and long vowels. Based on the maxim that one symbol can be utilized for two purposes, Dayananda argued this as essentially an algebraic idea; a letter is used as a part of the alphabet in one sense/context while an unknown number or a variable in another. Joseph (1991) found that Panini's efforts in Sanskrit grammar to increase the language facility became apparent in the mathematical literature. This suggests that mathematical symbols grew out of the outcomes of linguistic developments in India. It is known that Vedic times great competition existed amongst scholars motivating them to formulate verses, statements or rules in precise form utilizing least amount of alphabetical letters as possible (mantras or sutras). This is indeed the function of algebraic forms.

As shown in this study, the lwork done in algebra from ancient times show a gradual development from the rhetorical stage to symbolism in algebra. Research by Maharaji (1965) seems to confirm Dayananda's beliefs. Maharaji showed how algebraic rules and generalized arithmetic were essentially derived from the Vedic tradition. While his work has been somewhat criticized Sharma (2009) cannot be (http://www.scribd.com/doc/12794819/Bhu-Dev-

SHARMA-Origins-of-Math-in-Vedas) for he presented more evidence from Vedas (Dayananda, 1875, 1958) by making the following points:

- $\quad$ The numbers $1,2,3, \ldots 9$, with 9 as the largest single digit find mention in the 'richaas' and mantras of the Vedas

- There is enough evidence that a method to denote 'zero' was known to Vedic seers

- The Vedas refer to what in the modern terminology are called 'sequences of numbers

- That the idea of fractions, both unit and others, has also found clear mention in Vedas

Moreover, Chandogya Upanishad (600BC) uses the word "rasi" (translated as a "heap"); to represent an unknown amount not different to the Egyptian use of a heap of pebbles alluding to the modern " $x$ " (Balsham, 1975). There is little reason to believe the Indian knowledge was based on Egyptian work because the Upanishads are independent works (Gabre, 1897). It appears "rasi" was later written as "res" meaning unknown in Latin. Dayananda's ideas were indeed appropriate as the development appears to have occurred from rhetorical (concrete) to syncopated (abbreviated pictorial) and to symbolic algebra.

Development of symbolic algebra in India (800BCAD1500): It is known that a well developed arithmetical system is needed before generalized arithmetic and algebraic ideas may be grasped in learning of mathematics (Norton and Irivin, 2007; Sfard, 1994; Stacey and MacGregor, 1999). Laplace (O'Connor and Robertson (2000) from St Andrews University, Scotland-History of Mathematics Archive) confirmed that this was the situation in ancient India.

The ingenious method of expressing every possible number using a set of ten symbols (each symbol having a place value and an absolute value) emerged in India. 


\section{J. Math. \& Stat., 6 (4): 468-480, 2010}

The idea seems so simple nowadays that its significance and profound importance is no longer appreciated. Its simplicity lies in the way it facilitated calculation and placed arithmetic foremost amongst useful inventions. The importance of this invention is more readily appreciated when one considers that it was beyond the two greatest men of Antiquity, Archimedes and Apollonius.

Vedic Indians have made lasting contributions in several areas such as philosophy, grammar (Panini, 300BC) and number as evidenced by the development of the present day number system and of course the symbol of zero as a placeholder and much of arithmetic. In relation to algebra the judgement was suspended, but the current views have now changed. For example, Hankel quoted in both Cajori (2007) and Singhal (1969) suggested that the Vedic Indians invented algebra defined as "the application of arithmetical operations to both rational and irrational numbers of magnitudes" (p.97). Mason (1962) in his history of the sciences confirmed that Vedic Indians are now credited with the development of not only our modern number system but also the development of generalized algebraic operations. More precisely though, Cajori (2007) stated in "both the spirit of arithmetic and algebra of modern times are essentially Indian" (p.97).

Cajori (2007), we find evidence that Vedic Indians were one of the first to recognize the existence of totally negative quantities. It is not certain whether the Chinese notion of negatives had any influence because it was in the early centuries of the Christian era. Interestingly however, the ancient philosophy in India allowed Indians to be more prepared and thus readily accept the negatives and positives as such ideas were deep rooted in Vedic thinking; in aspects of karma, not allowing negativity to dominate in one's thinking, striving to reach balance state known as "Mokhsa" ultimate goal of all Hindus; these were ideas well grounded into Indian thought (see Vedas, Upanishads). By contrast we note in Kline (1980) great European mathematicians such as Cardan named negative roots as fictitious, Viete discarded negative roots entirely and Descartes called them false on the grounds they were meaningless. Given what such great mathematicians said, it is rather significant that the Hindus overcame such difficult conceptions more easily to leap to negatives. In Indian mathematics we do in fact find evidence of modern school type applications -the idea of "debts" and "possession" as conception of opposites; also we see the concept of opposite directions on a number line in AD700 (Cajori, 2007; Singhal, 1969; Kline, 1980).

It is not difficult to prove that many of these mathematical ideas and concepts alluded to above are in the Vedas and Upanishads. The first invocation mantra of Isha Upanishad refers to the "infinite coming out of infinite yet remains infinite". Kena, Katha and Prasna Upanishads are early achievements in philosophy that appear to have aided the development of zero and negatives. Statements such as greater than the greatest and smaller than the smallest, omnipresent, all or none, real and unreal or balance between divergent tendencies are common descriptions in earlier Indian works (600BC or earlier). So the concepts of zero, negative number, real and unreal (even imaginary number) and balance (=) are not only mathematical discoveries but are deep rooted in Vedic thought. The conception of Sunya (void or nothingness) appears in Hindu and Buddhist philosophies; the symbols such as for AUM () being shortest name for the universal soul or energy that permeates all and SWASTIKA (ㄴ) also representing the concept of being in all directions and omnipresent, among other symbols were commonly used to represent abstract and more difficult concepts. The symbols (existed from the time of Rig Veda dated around 1500BC; Balsham, 1975) were utilized in meditation helping the Hindus rise above concrete labels and thus abstract, realize the power and utility of symbols: but it is the use of letters of the alphabet, objects and symbols to represent abstract quantities such as Aum as one universal absolute that is imminent but at the same time transcendent aided their success in algebraic thinking. One notes the use of letter of the alphabet to represent a number of aspects of the absolute at the same time using Aum and Swastika.

Symbolism is seen as the modern India but today it is mostly at the concrete level while in the past it was used to raise levels of abstraction from concrete positions thus raising spirituality of individuals; this was believed to influenced intellectual abilities and indeed may have facilitated mathematical development from concrete to abstract. Current research shows there was a clear difficulty in the notion of abstraction from arithmetic to algebra historically and this is mirrored in student learning at high schools today; algebra continues to cause difficulties for students (Cooper et al., 1999; Herscovics and Linchevski, 1994; Norton and Irvin, 2007; Usiskin, 1988). It seems reasonable to assume that progress could then only occur when one introduces the use of symbols to represent the unknowns and uncertain quantities (Sfard, 1995). In the Vedic tradition, the use of symbols allowed one to move from "ignorance" (avidya) to abstraction-absolute one (vidya) via meditation (see Upanishads and Yoga). Abstraction and higher order thinking is developed by frequent questioning, a method of learning noted in the philosophical texts such as the Vedas and Upanishads (Kena, Prasa Upanishads, 600BC). This type of analysis 
and synthesis leads one to rise above the use of object symbols to words and phrases, based on decimal number system and Sanskrit proper (Panini, 300BC). Once the Hindus had developed the alphabet, invented the symbol for numbers including zero it was then not difficult to use alphabetic symbols to denote unknowns. The progress in India continued gradually with the development of rules for arithmetic and algebraic calculations.

There was a brief period of Vedic decline and this occurred due to the gradual movement towards the highly ritualistic interpretations of aspects of Vedic religion; other religions began to replace it. Jainism $(150 \mathrm{BC})$ is a religion and philosophy founded in India around the 6th century $\mathrm{BC}$ became a focus during this period (a religion that is known for no killing or harm to anything at all on earth). The idea of vegetarianism continued from Vedic times to a more extreme position in Jain literature. However, historians often consider this period to be a rather dark period in Indian mathematics but this appears far from the truth. It is now known that many mathematical ideas were developed during this time. In fact some think Aryabhata (see later) was simply summarising the mathematical developments of the Jaina period. The topics considered in this Jain period were the theory of numbers, arithmetical operations, geometry, operations with fractions, simple equations, cubic equations, quartic equations and permutations and combinations. The Jain period saw a well developed theory of the infinite containing different levels of infinity (notions well grounded in Vedas) and some knowledge of indices and logarithms to base 2 .

After this stage, advancements in arithmetic, algebra and trigonometry were notable (Singhal, 1969) for example, Ayrabhata (I) (see Dutta, 2002; Volodarsky, 1977). Kurian (1976) stated that Aryabhata (I) (Volodarsky, 2000) was one of the first users of algebra (now Encyclopaedia Brittanica supports his claim). In his work, Aryabhata (I) (AD499) expressed large numbers using syllables of the Sanskrit language (Singhal, 1969). Singh cited in Singhal (1969) said, "Aryabhatiya contains practically the whole of arithmetic that we teach today in our high schools" (p.398). The Vedic Indians progressed further to calculate square roots and cube roots, to utilize coefficients in algebraic equations, to develop rules for moving terms from one side to another, to categorize equations according to their degrees and to solve quadratics and indeterminate equations. Most significantly, the Vedic Indian solutions to indeterminate equations have been noted as being one of their greatest contributions to algebra (Dutta, 2002; Cajori, 2007).
Following the tradition of Aryabhata (I), in AD598-660 Brahmagupta (AD628) was the first to supply a complete solution of the Quadratic equation (Singhal, 1969) and the use of the completing the square method. While Chinese and Arab works contain some evidence of earlier solutions, it is to be noted that the spread of Buddhism initiated the spread of much knowledge to the Eastern countries (Singhal, 1969). It is also known that Arabs translated many Indian texts including one on numbers and arithmetic and spread the Hindu number system to the west. Not only were Vedic texts taken to many eastern places, supported by the fact that Sanskrit and Devanagari characters have been found in several countries such as Indonesia, Vietnam and Japan of ancient times; it is also noteworthy that a form of martial arts known as Tai Kwan Do that originated in India was taken to the East by Buddhist monks (500-300BC). Many now accept that Alkwarzmi's work may not be original in that it is likely that he had prior knowledge of Hindu solutions or even Chinese works (Joseph, 1991).

Later, Brahmagupta's work was advanced by Mahavira in the ninth century. In the twelfth century, Bhaskara (II) continued the work advancing rules for finding permutations and combinations as well as inventing the fractional form. He was also the first to state that division by zero is infinity (incorrect); another concept alluded to in the texts involving numbers and philosophy. Following this period, the Arabs and Europeans made many advances in algebra but up to the 18th century most of the progress was in line with the Vedic Indians ideas (Singhal, 1969). Even today the symbols used in algebra are modified but the symbolism remains essentially Vedic Indian. As noted earlier, Cajori (2007) stated that in both the form and spirit of arithmetic and algebra of modern times are essentially Indian.

Algebra is often thought of as generalization of arithmetic. For example, Newton wrote a text on algebra and named it Universal Arithmetic. Maharaji's text Vedic Mathematics of the Vedas contained arithmetic formulas of which he cited 16. These were invented by the Vedic Indians as advanced rules that solved arithmetical problems quickly often referred to as "mental" mathematics in India. It is clear that underlying structures in such rules were algebraic (Joseph, 1991). Today however, algebra is more appropriately considered as an extension of arithmetic rather than simply generalized arithmetic.

Development of higher mathematics based on algebraic achievements: Although the decimal system 


\section{J. Math. \& Stat., 6 (4): 468-480, 2010}

of numbers are well noted in the Vedas (1500BC), the modern number system as we know it today was confirmed to have existed in 200-300BC during King Asoka's reign. The first outsider to acknowledge the Indian decimal number system, Severus Sebokht (AD622) who said, "I will omit all discussion of the sciences of the Hindus; their valuable method of calculation; their computing which surpasses, all description. I wish to say that this computation is done by the means of nine signs" (Mason, 1962). In terms of higher mathematics, Albiruni (1017-1030) stated much later, "I can only compare their astronomical and mathematical literature ... to a mixture of pearl shells and sour dates, or costly crystals and common pebbles. Both kinds of things are equal in their eyes, since they can not rise themselves to methods of strictly scientific deduction" (Mason, 1962). Leaping to generalizations, following intuition, risk taking and making mistakes were seen as a learning process in India; for example, Indians proceeded to correct the decimal place of $\pi$ overtime and indeed were one of the first to give it accurately in ancient times; the division by zero to be infinity while incorrect is not as farfetched for as a number gets closer to zero in the denominator the result does get rather large (limit concept). There is evidence that shows that intuition and boldness of risk taking indeed played a part in their thinking. Yet this movement to and fro from extremes tendencies was one of problem solving tools that became the reason for their success in algebra. When the Greeks made a clear distinction between numbers and magnitudes, the Vedic Indians were able to freely move from magnitudes to numbers and from numbers to magnitudes (Cajori, 2007). The quoted "mixture of pearl shells and sour dates" can then be easily explained as learners erring but learning from it.

What is more important however is to comprehend the high reliance on oral tradition especially in earlier Vedic times; till today, this is noted in the Indian "gurushishya" learning method, classical music tradition, philosophy and religions - for example, all the Vedas are memorized by Brahmans. It is not surprising then many deduce that their mathematical works would also have been orally transmitted. For this reason it seems that Hindu works do not include written proofs and chains of reasoning. Indeed it is the lack of deduction and proof the Vedic Indians are often criticized; the tradition suggests that they passed on knowledge in an "oral" tradition and importantly to only those capable (Mason, 1962). This meant the logic and systematic reasoning steps were memorized by individuals who were usually Brahman considered capable of such memory demands; a similarity is seen in the
Upanishads (Katha) where individuals in search of the knowledge of "atman" (universal spirit or god) to undergo much sacrifice and perform intense meditation under the guidance of a learned Guru before the student could begin to learn or question such deeper and sacred knowledge only given orally (Cajori, 2007; Balsham, 1975); the teacher-pupil relationship is not dissimilar to Plato's times as noted by Gabre (1897), who in his text went on to show many more similarities of Greek work to Indian works of earlier times.

Even the so called father of European algebra, Diophantus may have received his inspiration from India. Cajori (2007) said, "If his works were not written in Greek, no one would think for a moment that they were the product of Greek mind ... Except for him, we should be constrained to say that among the Greeks algebra was almost an unknown science" (p.60). While no direct proof exists, Diophantus' ideas were suddenly posed into Greek mathematics and were contradictory to what was developing in Greek mathematics at the time. Not to dissimilar to Pythagoreans' work and belief in reincarnation and number theory that relates closely to Sankhya Philosophy of India (Gabre, 1897) and novel to Greek works. In fact, Gabre (1897) argued that Pythagoras obtained the square root of two from India. Singhal (1969) said that evidence exist that show the flow of information from India to Alexandria existed at that time so the Greek philosophical works could probably be based on Indian teachings and Cajori (2007) appears to confirm this view.

More specifically, Struik (1987) stated that the first solution to the indeterminate equations of the first degree, $a x+b y=c$ where $a, b, c$ are integers, is found in Brahmagupta's (AD628) work and therefore it is probably incorrect to name these equations Diophantine equations (Cajori, 2007; Singhal, 1969). When Diophantus accepted only one rational solution for an equation, the Indians went on to accept all possible integer solutions. Importantly, Cajori (2007) noted that the "cyclic method" used by Indians in indeterminate quadratics is one of the greatest invention in the theory of numbers before the time of Lagrange. He added that the first incisive work on the now named (incorrectly, it seems) Pell equation was done in Brahman scholarship.

In sum, there was much similarity between the Manichaeans, Neoplatonists and Gnostics works and the Indian works (Cajori, 2007). Diophantus' contribution appeared to be divorced from geometry and surprisingly analytical and his system is rather similar to the Vedic Indian methods (Singhal, 1969); clearly, Pythagorean works were contradictory to his era as well. According to historical events, it appears 
likely that Diophantus's inspiration was based on Indian works.

As noted earlier, many thought there was about 200 years of no mathematical work in India even when there was such a developed history but this was far from the truth. The mathematicians of Kerala had anticipated some of the results of the Europeans on the calculus by years and this was first noted by Whish in 1835. Whish wrote the work had... laid the foundation for a complete system of fluxions ... and more importantly, the works is... abound with fluxional forms and series to be found in no work of foreign countries. (O'Connor and Robertson, 2000).

It is clear from Nilakantha's (1444-1544) writings that his knowledge of several branches of Indian philosophy was at a high level. Sundararaja referred to Nilakantha as sad-darshani-parangata. Sad means 6 and dharshana means philosophy: that is, Nilakantha had mastered the six systems of Indian philosophy. In debates he used the Mimamsa authority (also adhered by Dayananda), to establish his view-point. He extensively used Mimamsa authority quotes from Pingala's chandas-sutra, scriptures, Dharmasastras and so on. Nilakantha's work shows the derivation of Leibniz-Gregory series before them:

$$
\frac{\pi}{4}=1-\frac{1}{3}+\frac{1}{5}-\frac{1}{7}+\frac{1}{9}-\frac{1}{11} \ldots
$$

and:

$$
\frac{\pi}{4}=\sqrt{12}\left(1-\frac{1}{3.3}+\frac{1}{5.3^{2}}-\frac{1}{7.3^{3}}+\frac{1}{9.3^{4}}-\frac{1}{11.3^{5}} \ldots\right)
$$

The two series are more interesting in that it used the geometrical definition of $\underline{\pi}$ as the ratio of circumference and diameter of a circle. Furthermore, his work on second differences should also be noted. The differences are studied geometrically using the property of circle and of similar triangles. Denoting by $\Delta_{2}(\sin \theta)$ and $\Delta_{2}(\cos \theta)$, the second differences of these functions, a form of $\Delta_{2}(\sin \theta)$ is noted in Nilakantha's work:

$$
\Delta_{2}(\sin \theta)=-\sin \theta\left[\sin \left(\frac{\Delta \theta}{2}\right)\right]^{2}
$$

Nilakantha also made use of a result involving the differential of inverse sine function expressed in modern notation as:

$$
\delta\left(\sin ^{-1} \mathrm{e} \sin \omega\right)=\frac{\mathrm{e} \cos \omega}{\sqrt{1-\mathrm{e}^{2} \sin ^{2} \omega}} \delta \omega
$$

In a similar tradition the continued interest in algebra and number theory is evident in the works of the great Srinivasa Ramanujan, an untrained Brahman mathematician of this century (Hardy, 1980). Srinivasa Ramanujan, inspired by the theory of numbers, often leapt into generalizations (algebraic equations) while others could only manage intermediate steps. He helped to create Rogers-Ramanujan identities including others. Hardy cited in Balsham (1975) stated that Srinivasa had "an insight into algebraic formulae, transformation of infinite series and so forth, that was most amazing. On this side most certainly I have never met his equal and I can compare him only with Euler and Jacobi" (p. 160). Ramanujan died at the age of 32 but there is much literature on Ramanujan today (Srinivasa, 1998). Indeed a continuation fascination of $\pi$ is seen in one of his many identities:

$$
\frac{1}{\pi}=\frac{2 \sqrt{12}}{9801} \sum_{\mathrm{k}=0}^{\infty} \frac{(4 \mathrm{k}) !(1103+2639 \mathrm{k})}{(\mathrm{k} !)^{4} 396^{4 \mathrm{k}}}
$$

Greek and Vedic Works in ancient times: It is often believed that Egyptians and Babylonians as being the height of civilisation and of mathematical skills around the period of the Indus civilisation. However, Childe (cited in O'Connor and Robertson (2000)) in New Light on the Most Ancient East (1952) wrote.

India confronts Egypt and Babylonia by the 3rd millennium with a thoroughly individual and independent civilisation of her own, technically the peer of the rest. And plainly it is deeply rooted in Indian soil. The Indus civilisation represents a very perfect adjustment of human life to a specific environment. And it has endured; it is already specifically Indian and forms the basis of modern Indian culture (p.2).

In general, when compared with Greek progress in algebra, Hindu works appear to be rather superior (Kline, 1980). The Greeks experienced difficulties due to improper symbolism in their number system. This may be mainly due to their immature conception of number. In early works, the Greeks conceived number as spatial extension or length more so than "number" as an abstraction (Singhal, 1969). It seems the lack of sustained development of algebraic ideas may have caused further difficulties such as the Greek failure to solve the indeterminates to such a state as achieved by the Vedic Indians. In summing up the achievements of Indians and Greeks, Singh (cited in Singhal (1969)) stated that while logic and systematic treatment are outstanding features of Greek geometry, "boldness of conception, abstraction, symbolism and ingenuity are the main features of Indian mathematics" (p.167). 


\section{J. Math. \& Stat., 6 (4): 468-480, 2010}

Moreover, although Arabs must be credited with developing some algebra (cubics based on geometry) later, it is now well accepted that they were consolidators and transmitters of much of Indian and Greek knowledge rather than the developer or competent user of early symbolic algebra. The older historical authors have indeed changed their views in more recent times; for example, the historian, Eves (1990) stated in his text that Alkwarizmi's work in algebra was not original.

Geometry: Indians used algebra freely and saw its usefulness over geometry and trigonometry as will be seen later. The Vedic Indians had a reasonable knowledge of geometry due to practical calculations needed in their rituals in early Vedic times and much of the knowledge is still evident in the text named Sulba sutras 800-500BC (Balsham, 1975). Although the geometry developed during this period appears to be at an empirical and practical level, some of the Indian constructions almost certainly needed much geometrical ingenuity. The ritual related geometry of the Sulba sutras included rules for the construction of squares and rectangles, the relation of the diagonal to the sides, equivalent rectangles and squares, equivalent circles and squares, conversions of oblongs into squares and vice versa and the construction of squares equal to the sum and difference of two squares. Importantly, in such rules prior knowledge of the Pythagorean theorem is clearly evident. Also included in the text are approximations in terms of unit fractions. Such results are correct to five decimal places. It is clear that Vedic Indians also knew the mensuration of the triangle, the parallelogram, the rectangle and the rectangular parallelepiped. Further, they studied the mensuration of the circle, the cone, the sphere and the pyramids; the constant ratio between the circumference and the diameter appeared later. It has been suggested that Heron of Alexandria (100BC) may have been influenced by Sulba sutras, composed sometime between 800-500BC (Joseph, 1991) and this certainly cannot be disregarded (Cajori, 2007; Singhal, 1969). For example, the Bodhayana Sutras (800-600 BC) contain a general statement of the Pythagorean theorem, an approximation procedure for obtaining the square root of two correct to five decimal places and a number of geometric constructions (Krishnamurthy, 2007; Kuchemann, 1981). The works include an approximate squaring the circle and construction of rectilinear shapes whose area is equal to the sum or difference of areas of other shapes. The Bodhayana version of the Pythagorean theorem is as follows: "The rope which is stretched across the diagonal of a square produces an area double the size of the original square". Remarkably, the square root of two is obtained as "1.4142156 ... [the true value being 1.414213...]. The fact that such procedures were used successfully in the Sulba sutra to operations with other irrational numbers disputes the opinion that the Sulba sutra was borrowed from the Babylonians and but rather confirms the earlier proposition. In fact, the Babylonians only calculated of the square root of two and used the sexagesimal rather than decimal. Furthermore, Krishnamurthy (2007) added that:

The achievement of geometrical constructs in Indian mathematics reached its peak later when they arrived at the construction of Sriyantra, consisting of nine interwoven isosceles triangles, four pointing upwards and four pointing downwards. The triangles are arranged in such a way that they produce 43 subsidiary triangles, at the centre of the smallest of which there is a big dot called the bindu. The difficult problem is to construct the diagram in such a way that all the intersections are correct and the vertices of the largest triangles fall on the circumference of the enclosing circle. In all cases the base angles of the largest triangles is about 51.5 degrees. This has connections with the two most famous irrational numbers of Mathematics, namely $\pi$ and $\phi$. (p.4; see also Kulaichev, 1984)

In his works, Brahmagupta gave Hero's formula of the area of a triangle in terms of the sides of a triangle which suggests he may have been familiar with Hero's form. However, he made a significant extension of this formula to include the area of a cyclic quadrilateral not found in Hero's works so we await confirmation of whether Hero's form was in fact known.

Max Muller on India: Muller (1899) certainly changed his views after learning of Dayananda's research but one of his quotes late in life is worthy of mention given what has have unearthed since in India.

"If I were asked under what sky the human mind has most fully developed some of its choicest gifts, has most deeply pondered over the greatest problems of life and has found solutions of some of them which well deserve the attention even of those who have studied Plato and Kant, I should point to India. And if I were to ask myself from what literature we who have been nurtured almost exclusively on the thoughts of Greeks and Romans and of the Semitic race, the Jewish, may draw the corrective which is most wanted in order to make our inner life more perfect, more comprehensive, more universal, in fact more truly human a life...again I should point to India”. 
It seems that Vedic Indians had calculated that speed of light close to the value of found by astrophysicists today (Kak, 2007; Londhe, 2008). It is important to note that ancient Vedic art was of a high standard some of them rather ancient 40000BC. Also, binary arithmetic was used in writing it there developed long before the West (Kak, 2007; Londhe, 2008). In fact, researchers in NASA have elevated the ancient language of Sanskrit language to a rather high level of linguistic development (Briggs, 1985).

In this paper only the Vedic Indians works are presented in relation to their achievements and indeed how their works relate to algebra and algebraic thinking and application. Prakash (1989) provided evidence of the influence that Vedas and its related literature on Indian mathematics. He argued that it was the nature of the philosophical tradition and its related ideas that seemed to have led to the development of the Indian decimal system, arithmetic, geometry, algebra and trigonometry. This view was supported by Joseph (1991) - that the work on early astronomy eventually led to the development of algebra, analysis and trigonometry. Sustained development in algebra over time led to the development of Newton-Stirling formula to second order differences and Newton-Gauss interpolation formula mentioned earlier (known as early as AD600-AD850) and Taylor series to second order years before Taylor (Joseph, 1991; O'Connor and Robertson, 2000).

\section{CONCLUSION}

In light of the research in the paper some important considerations are drawn. First, arithmetic and algebra were both well developed in India. For example, it was not until 16th century that Recorde and Viete among others initiated the use of symbols in the manner it was used earlier in India.

Second, the Vedic mathematics around 5000BC must have gradually developed from the time of Harappa through to the Vedas to its heights somewhere around AD500-1200. If it is a given that advancements are due to the shoulders of giants before us clearly Aryabhata and others must have giants before them; particularly when much of works were novel when compared with the rest of the world's development over time. It is well known, due to the numerous invasions India, that many books containing other mathematical knowledge have been lost. The discovery of Bakshali manuscript dated around 100BC, evidence of the works in Kerala mathematics and in Struik (1987) findings we gain added support of this belief.
In revising his text, Struick (1987) was more cautious about Indian achievements. Although he said, "It is now apparent that Babylonian mathematics was far more developed than its Oriental counterparts. The judgment may be final" but equally conceded that "Further study of Hindu mathematics may still reveal unexpected excellence (pp.21-22). And more importantly, he advanced that "Ancient India still yields many more mathematical treasures; some we now know, for instance, that the well known GregoryLeibniz series for $\pi / 4$ can already be found in a Sanskrit manuscript ascribed to Nilakantha, AD1500" (pp.66-67) (Joseph, 1991).

Third, Dayananda was the first researcher to state with evidence that algebra was developed in India in mid 1800AD insisting on linguistic competence of Sanskrit being the basis. This in depth review shows that he was in fact correct. Dayananda was one of the great intellectual and social reformers of modern India (Basham, 1975; Singhal, 1969). Indeed it was his indepth research that refuted Muller's colonial driven translations is notable in "The Introduction to the Commentary on Vedas" among others. His quality of research provided the motivation for India to revisit the knowledge of the Vedas and thus provided the platform for modern scholars to pursue important questions. For example, he insisted that higher mathematics and sciences are in the Vedas. In Professor Max Muller's biography, he stated:

"To Swami Dayananda everything contained in the Vedas was not only perfect but he went one step further and by their interpretation, succeeded in persuading others that everything is worth knowing; even the most recent inventions of modern science were alluded to in the Vedas. Steam engine, electricity, telegraphy and wireless marconigram were shown to be known in the germs of poets of the Vedas".

Based on his analysis, Arvind Gosh Yogi writes: "Dayananda affirms that the truths of modern physical science are discoverable in the hymns. There is nothing fantastic in Dayananda's idea that Veda contains truth of science as well as truth of religion. I will even add my own conviction that Veda contains other truths of science the modern world does not at all possess and in that case Dayananda has rather understated than overstated the depth and range of Vedic wisdom".

In sum, Swami Dayananda's knowledge of Sanksrit and the Vedas provided a credible challenge to Oxford based translations of Muller and others. His evidence facilitated progress at the time and generally 


\section{J. Math. \& Stat., 6 (4): 468-480, 2010}

halted the denegration of the Vedic literature and Hindu credits generally.

In conclusion, the ideas and concepts of zero, base ten, arithmetical and algebraic thinking is deep rooted in Vedic philosophy. It is then not surprising then the Vedic India reached such heights in mathematics at such an early period in human history. The arithmetic and algebra of the Vedic people were transmitted to the West by the Arabs and as such permeates all our developed work today. Indeed, there is a need to pay tribute to them for on their shoulders lie much of the mathematics of today. This study presents a comprehensive historical perspective and summary of the Vedic Indians, highlighting the indebtedness of the world to the ancient philosophy and motivation to understand the physical and spiritual aspects of knowledge. In particular, their mathematical achievements relating to algebra is highly notable in that they were bold, intuitive and leapt to generalizations and abstractions without often providing written proofs thus taking risks in problem solving. In doing so not only did they give us the decimal system including zero but most importantly laid the foundations and developed much of what we know today as the science of the unknown: namely, algebraic thinking and algebra.

Implications for the teaching of algebra and higher mathematics: In order to overcome the difficulties of abstraction one has to take risks, follow intuition and move constantly between the notions of variables such as the letter standing for an object for example; a fixed number, a generalized number and a variable quantity. (Kucheman, 1981: Usiskin, 1988). Because the variable refers to a various things in mathematics one has to actively operate at different levels when dealing with letters in mathematical problems (Usiskin, 1988). Thus the teaching of algebra should promote risk taking behaviours and thus include problems that require the use of concrete, pictorial and abstract or symbolic notions simultaneously. Also, it is evident that reflective, introspective, metacognitive and creative processes played an important role in the development of algebra. The Vedic mathematicians were able to relate and connect the knowledge of abstract notions from their early concrete and pictorial items such as idols and at the same time represent all concrete ideas with using abstract symbols. For example, Kulaichev (1984) stated that the achievements in constructing spherical triangles by Indian geometers requires "higher mathematical knowledge which ancient Indians did not possess" (p.292). He went on to suggest that the unknown cultural and historical alternatives to mathematical knowledge may be responsible such as highly developed tradition of "special imagination": thus suggesting a strong link between risk-taking, delving into the unknown as well as higher order thinking skills fuelled by affective variables, such as beliefs, motivation, strong persistence and so on. The affective domain variables such beliefs and motivation helped the Indians achieve much of their mathematical advancements. For example, through sustained analysis the Indians soon realized that algebraic knowledge could be applied to improve the speed with which religious based astronomical calculations could be done. This highlights the importance of considering variables such as motivation, persistence in the learning and teaching of algebra. The contexts of learning should be one that encourages engagement in higher order skills of abstraction and so on.

More specifically, there are a number of implications for the teaching of algebra should use of both real life, imaginative and creative problems to help students to move between numbers and magnitudes rather than taking a static and an unchanging view. This can be achieved through the use of problems whose solutions require the use of all three modes of understanding; namely, concrete, pictorial and symbolic; with symbolic being the ultimate goal. Within this framework, higher order skills such as reflection, metacognition, introspection and creative thinking should be explicitly encouraged through the use of special non-routine type problem solving. High levels of motivation and strong beliefs in achievement developed persistence in India all based on their need to understand the physical world. Such a process involved risk taking and even following of one's intuition that may lead to errors on the way to mastery. It is clear that real life practical, philosophical and religious push motivated the development of symbolic algebra in Vedic times. A similar process can be replayed in learning environments with the use of rich context based problems that stimulate and motivate students to realize application and transfer of knowledge. The progress from arithmetic to algebra shows that the ancient learning of algebra in India was is in line with current emphasis in mathematics education.

\section{REFERENCES}

Bailey, D.H. and J.M. Borwein, 2010. The greatest mathematical discovery. http://escholarship.org/uc/item/0sp6t6h5; jsessionid =E85CFDF7FA2E8C948C15B57F6CC0C1B7

Basham, A.L., 1975. A Cultural History of India. 1st Edn., Oxford: Clarendon Press. ISBN-10: 0195639219, pp: 585. 
Briggs, R., 1985. Knowledge representation in sanskrit and artificial intelligence. Artificial Intel. Magaz., 6: 32-39. http://www.aaai.org/ojs/index.php/aimagazine/artic le/viewArticle/466

Cajori, F., 2007. A History of Mathematics. 1st Edn., Muschamp Press, 2007, New York. ISBN: 1406709190, 9781406709193, pp: 408.

Carifio, J. and R.J. Perla, 2010. Towards the decline and fall of radical and educational constructivism (Mark I). Current Res. Psychol., 1: 1-15. DOI: 10.3844/crpsp.2010.1.15

Cooper, T.J., A.M. Williams and A.R. Baturo, 1999. Equals, expressions, equations and the meaning of variable: A teaching experiment. In Making the difference: Proceedings of the 22nd Annual Conference of the Mathematics Education Research Group of Australasia, Adelaide, South Australia, MERGA, July 4-7, pp: 589. ISBN-09596844-9-2

Dunbar, S.G.B., 1949. A History of India from the Earliest Times to Nineteen Thirty Nine. 4th Edn., Nicholson I Limited, London, pp: 659.

Dutta, K.A., 2002. Mathematics in ancient India. Resonance, 7: 4-19. http://www.ias.ac.in/resonance/April2002/pdf/Apri 12002p4-19.pdf

Eves, H., 1990. An Introduction to the history of mathematics. 6th Edn., The Saunders Series, New York, ISBN: 0030769299, pp: 775.

Gabre, R., 1897. The philosophy of ancient India. 1st Edn., The Open Court Publishing Company, Chicago, pp: 96. http://www.amazon.com/gp/search?index=books\&l inkCode $=$ qs $\&$ keywords $=1417960582$

Hayashi, T., 1997. Aryabhata's Rule and table of sinedifferences. Historia Mathe., 24: 396-406. DOI: 10.1006/hmat.1997.2160

Herscovics, N. and L. Linchevski, 1994. A cognitive gap between arithmetic and algebra. Educ. Stud. Mathe., 27: 59-78. DOI: 10.1007/BF01284528

Joseph, G., 1991. The crest of a peacock: Non European Roots of Mathematics. 1st Edn., Penguin, London. ISBN: 1850433593, pp: 384.

Joseph, G.G., 2000. The Crest of the Peacock: The Non-European Roots of Mathematics. 2nd Edn., Princeton, NJ: Princeton University Press, ISBN: 0691006598, pp: 455.

Kak, S., 2007. Louisiana State University (2007, February 15). Professor Resolves Einstein's Twin Paradox. http://www.sciencedaily.com/releases/2007/02/070214220824.htm
Kaye, G.R., 1915. Indian mathematics. 1st Edn., Amd Simlaz, Calcutta, ISBN: 145155446X, 9781451554465, pp: 114.

Kline, M., 1982. Mathematics the loss of certainty. 1st Edn., Oxford University Press, New York. ISBN: 0195030850, pp: 366.

Krishnamurthy, V., 2007. History of mathematics-The Indian Contribution. http://www.krishnamurthys.com/kvforp/VK1/Histo ry_Maths_Indian_contribution.html

Kuchemann, D.E., 1981. Chapters on algebra, geometry and integers. In: Children's Understanding of Mathematics, Hart, K. (Eds.). Murray, pp: 82-87.

Kulaichev, A.P., 1984. Sriyantra and its mathematical properties. Indian J. History Sci., 19: 279-292. http://www.new.dli.ernet.in/rawdataupload/upload/ insa/INSA_1/20005abd_279.pdf

Kulke, H. And D. Rothermund, 1990. A history of India. 4th Edn., London: I Routledge. ISBN: 0415-32919-1, pp: 432.

Kurian, G.T., 1976. Historical and Cultural Dictionary of India. 1st Edn., New Jersey: The Scarecrow Press, Inc. Metuchen, ISBN: 0608152307, 9780608152301, pp: 331.

Londhe, S., 2008. Tribute to Hinduism: Thoughts and Wisdom spanning continents and time about India and her culture. 1st Edn., Pragun Publications, Delhi, pp: 549. ISBN: 8189920669, 9788189920661

Mason, S.F., 1962. A history of the sciences. 2nd Edn., Collier Books, New York. pp: 638. http://www.questia.com/PM.qst?a=o\&d=3551153

Muller, M., 1870. Chips from a German Workshop. 2nd Edn., Longmans, NY., pp: 544. http://www.worldcat.org/title/chips-from-agerman-workshop/oclc/2814121

Muller, M.F., 1899. Six systems of Indian philosophy. 1st Edn., Longmans, NY., pp: 618. http://www.amazon.com/gp/search?index=books\&l inkCode $=q s \&$ keywords $=1440065624$

Norton, S. and J. Irvin, 2007. A concrete approach to teaching symbolic algebra. In Mathematics: Essential research, essential practice. Proceeding of 30th MERGA Conference. Watson, J. and $\mathrm{K}$. Beswick (Eds.)., held in Perth, Australia. http://www.merga.net.au/documents/RP502007.pdf

O'Connor, J.J. and E.F. Robertson, 2000. Mathematics. McTutor History of Mathematics Archive.

Prakash, S.S.S., 1989. Founders of sciences in ancient. 1st Edn., Research Institute of Ancient Scientific Studies, India, pp: 675. 
Sfard, A., 1994. The gains and falls of reification - the case of algebra. Educ. Stud. Mathe., 26: 191-228. http://www.citeulike.org/group/862/article/378473

Sfard, A., 1995. The development of algebra: Confronting historical and psychological perspectives. J. Mathe. Behav., 14: 15-39. ISSN: 0732-3123

Sharma, B., 2009. Origin of math in vedas. [http://www.scribd.com/doc/12794819/Bhu-DevSHARMA-Origins-of-Math-in-Vedas]

Singhal, D.P., 1969. India and world civilization volume. 1st Edn., Michigan State University Press. Michigan, pp: 331. http://www.getcited.org/pub/100482318

Srinivasa, R.K., 1998. Srinivasa Ramanujan, a Mathematical Genius. East West Book Pvt Ltd, NY., ISBN-10: 818685214X, pp: 231.

Stacey, K. And M. MacGregor, 1999. Taking algebraic thinking out of algebra. Mathe. Teacher, 90: 25-38. ISSN: 1033-2170

Struik, D.J., 1987. A concise history of mathematics. 4th Edn., Dover Publications Inc, New York. ISBN: 0486602559, pp: 288.
Usiskin, Z., 1988. Conceptions of school algebra and uses of variables. In: Ideas of algebra K-12, Coxford, A. and A.P. Schulte (Eds.). Reston, VA: NCTM, pp: 8-19.

Vishnu, B.B., 2008. Scientific verification of Vedic knowledge.

[http://www.archaeologyonline.net/artifacts/scienti fic-verif-vedas.html, http://video.google.com/videoplay?docid=7678538 942425297587andq=vedicandhl=en\#]

Volodarsky, A., 1977. Mathematical achievements of aryabhatas. Indian J. History Sci., 12: 167-172. http://www.new.dli.ernet.in/rawdataupload/upload/ insa/INSA_1/20005af8_167.pdf

Volodarsky, A., 2000. Mathematical Achievments of Aryabhatas. http://www.math10.com/en/mathshistory/math-history-inindia/mathematical_achievements_of_aryabhatta.html

Zeigler, O., 1972. The world of south east Asia. 2nd Edn., Oswald Ziegler Enterprises, Sydney, ISBN: 0909586039, pp: 614. 